\section{Putative benefits of microalgal astaxanthin on exercise and human health}

\author{
Marcelo P. Barros, ${ }^{* 1}$ Sandra C. Poppe, ${ }^{1}$ Tácito P. Souza-Junior ${ }^{2}$

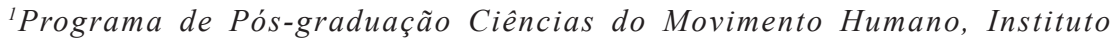 \\ de Ciências da Atividade Fisica e Esporte, Universidade Cruzeiro do Sul, \\ Brazil, \\ ${ }^{2}$ Departmento de Educação Física, Setor de Ciências Biológicas, \\ Universidade Federal do Paraná, Brazil.
}

Revista Brasileira de Farmacognosia Brazilian Journal of Pharmacognosy 21(2): 283-289, Mar./Apr. 2011

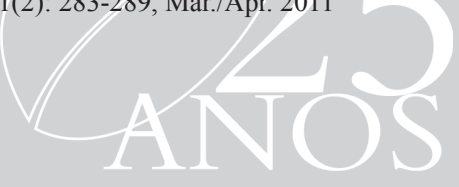

\section{Article}

Received 22 Dec 2010

Accepted 20 Jan 2011 Available online 22 Apr 2011 microalgae, but also commonly found in shrimp, lobster and salmon, which accumulate ASTA from the aquatic food chain. Numerous studies have addressed the benefits of ASTA for human health, including the inhibition of LDL oxidation, UVphotoprotection and prophylaxis of bacterial stomach ulcers. ASTA is recognized as a powerful scavenger of reactive oxygen species (ROS), especially those involved in lipid peroxidation. Both aerobic and anaerobic exercise are closely related to overproduction of ROS in muscle tissue. Post-exercise inflammatory processes can even exacerbate the oxidative stress imposed by exercise. Thus, ASTA is suggested here as a putative nutritional alternative/coadjutant for antioxidant therapy to afford additional protection to muscle tissues against oxidative damage induced by exercise, as well as for an (overall) integrative redox re-balance and general human health.
Keywords:
algae
antioxidant
astaxanthin
carotenoid
exercise
idative stress

ISSN 0102-695X

doi: $10.1590 / \mathrm{S} 0102-695 \mathrm{X} 2011005000068$

\section{Biosynthesis and biological properties of astaxanthin}

Carotenoids belong to a large class of compounds called terpenoids, which also includes steroids, retinol, calciol, and several secondary plant/ algal metabolites. These compounds are all derived from polymerization of isoprene units through the mevalonate biosynthetic pathway (Miao et al., 2010). Carotenoids are highly conjugated polyene systems with vivid colors, interesting chemical behavior and key physiological and nutrition functions (HigueraCiapara et al., 2006).

Carotenoids are widely distributed in both the plant and animal kingdoms and are ubiquitous in almost all living organisms. However, phytoplankton, bacteria, fungi, algae and plants are the only living organisms that produce carotenoids in significant quantities, whereas all other organisms obtain these pigments via their food chain. Astaxanthin (ASTA) is the most common carotenoid found in marine organisms and is particularly abundant in crustaceans and salmonid fishes (Christiansen et al., 1995). Some microalgal species like the freshwater alga Haematococcus pluvialis (Chlorophyceae) abundantly produce ASTA. In marine environments, ASTA is mainly produced by planktonic crustaceans such as copepods, but they are totally dependent on a constant supply of carbon backbone precursors - such as $\beta$-carotene and canthaxanthin - from algal food sources (Anderson et al., 2003). Scheme 1 depicts the major steps of ASTA biosynthesis in microalgal species.

The algal carotenoid ASTA is recognized as a powerful antioxidant both in vitro and in vivo, but is particularly efficient at scavenging peroxyl and alkoxyl radicals ( $\mathrm{ROO} \bullet$ and $\mathrm{RO} \bullet$, respectively) and quenching singlet oxygen $\left[\mathrm{O}_{2}\left({ }^{1} \Delta_{\mathrm{g}}\right)\right]$ (Barros et al., 2001; Palozza \& Krinsky, 1992). Recently, Polyakov et al. (2010) showed that ASTA and its mono- and dication forms can chelate $\mathrm{Ca}^{2+}, \mathrm{Zn}^{2+}$, and $\mathrm{Fe}^{2+}$ ions, although the lifetime of the radical ions formed electrochemically decreased in comparison to uncomplexed ASTA. Moreover, due to its spatial orientation perpendicular to the plane of lipid bilayers, ASTA increases the hydrophobicity in the central core of biological membranes, with several proposed biochemical/physiological consequences (Gabrielska \& Gruszecki, 1996). It has been shown that the ASTAinduced rigidifying effect in membranes could provide a coadjutant mechanism for antioxidant protection, more precisely, by limiting the permeation of redox-active promoters of lipid oxidation such as $\mathrm{Fe}(\mathrm{II})$ ions and $\mathrm{H}_{2} \mathrm{O}_{2}$ (Barros et al., 2001). It is also noteworthy that, even at nanomolar concentrations, ASTA was able to rebalance the mitochondrial redox state by: i) sustaining a high mitochondrial membrane potential; ii) stimulating 
the $\mathrm{pH}$ gradient; and iii) damping down the uncontrolled overproduction of reactive oxygen species (ROS), such as superoxide radical $\left(\mathrm{O}_{2}{ }^{-}\right)$and hydrogen peroxide $\left(\mathrm{H}_{2} \mathrm{O}_{2}\right)$ (Wolf et al., 2010).

There is convincing scientific evidence in support of an inverse correlation between a healthy diet and the occurrence of chronic diseases. One of the most important paradigms of recommended dietary guidelines is the high consumption of fruits and vegetables, notably those that are natural sources of carotenoids. However, of the more than 600 carotenoids already characterized in nature, only twenty have been properly identified in human blood and tissues (Rao \& Rao, 2007). The bioavailability of carotenoids in humans usually ranges from 10 to $50 \%$ of a given dose, due to their low solubility in gastrointestinal tract juices and poor absorption by the epithelial cells of the small intestine (Nagao, 2009). Stewart et al. (2008) suggested that the currently recommended doses of ASTA as a dietary supplement of 2-6 mg/day (0.07$0.1 \mathrm{mg} / \mathrm{kg} /$ day for an average individual weighing 60 $\mathrm{kg}$ ) are $\sim 800$ fold lower than the no-observed-adverseeffect-level (NOAEL). The endogenous lipoproteins chylomicrons and VLDL - with a minor contribution from LDL - concentrate the major fractions of ASTA in the plasma after oral absorption (Odeberg et al., 2003). Petri \& Lundebye (2007) showed that ASTA accumulates primarily in the spleen, kidneys, adrenals, skin, and eyes ( $>$ liver) of Rattus norvegicus rats after two weeks of oral administration. Interestingly, slight changes in the leucogram (especially of lymphocytes and neutrophils) were noted after seven days, but were restored after two weeks. Recent studies demonstrated that ASTA pharmacokinetic parameters were dosedependent after its intravenous administration (5, 10 and $20 \mathrm{mg} / \mathrm{kg}$ ), but dose-independent after higher oral administration, mainly due to the limited activity of hepatic cytochrome P-450, subclass 1A1/2 (Choi et al., 2010).

Regarding overall health properties, ASTA was proven to afford UV-photoprotection to skin/eyes (Cort et al., 2010), immune response enhancement (Bolin et al., 2010; Otton et al., 2010), protection against gastric ulcer induced by Helicobacter pylori (Kamath et al., 2008), and cardioprotective (Fassett \& Coombes, 2009), antihypertensive (Hussein et al., 2006), and anti-tumorigenic effects in humans (Nakao et al., 2010). Recent findings have shown positive effects of ASTA in obese mice fed a high-fat diet by reducing total plasma cholesterol and plasma/liver triglyceride

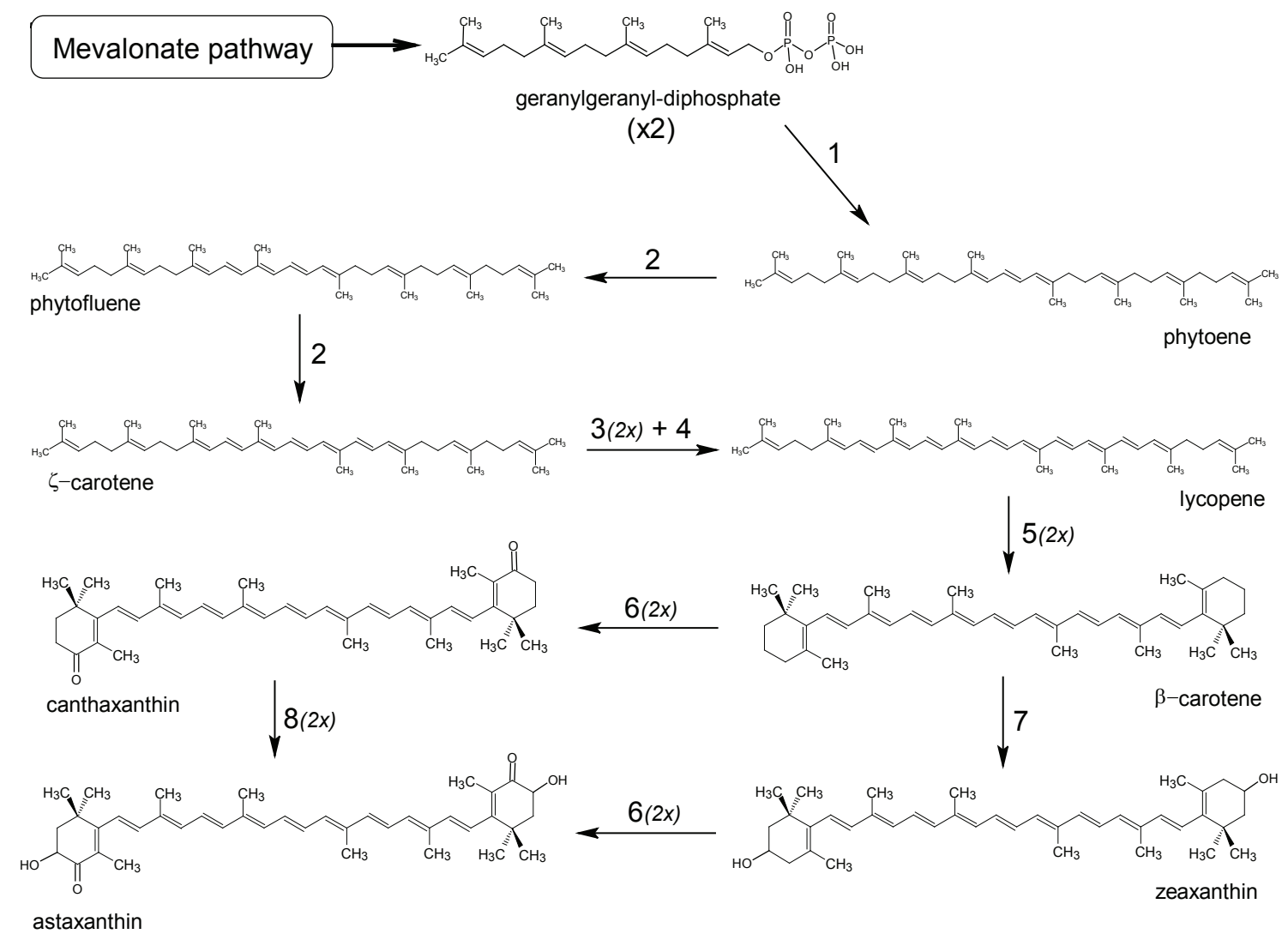

Scheme 1. Biosynthetic pathway of astaxanthin in plants and microalgae. Enzymes: 1, phytoene synthase; 2 , phytoene desaturase; 3 , $\zeta$-carotene desaturase; 4 , carotene isomerase; 5 , lycopene $\alpha$ - $\beta$-cyclase; $6, \beta$-carotene ketolase; 7 , $\beta$-ring hydroxylase; $8, \beta$-carotene 3',3-hydroxylase. Modified from Jin et al. (2003) and Cardozo et al. (2007). 
levels (Ikeuchi et al., 2007). In a randomized, placebocontrolled human study of metabolic syndrome - a modern-life disease characterized by hypertension, impaired glucose tolerance, and dyslipidemia - ASTA consumption (12 and $18 \mathrm{mg} /$ day; twelve weeks) efficiently restrained anomalous hyperlipidemia while HDL-cholesterol increased with 6 and $12 \mathrm{mg}$ ASTA/ day, in concert with measured levels of adiponectin (Yoshida et al., 2010).

The carotenoid ASTA has important applications in the nutraceutical, cosmetic, food and feed industries and, thus, has high economic value for biotechnology companies (Del Campo et al., 2007). Among the various ASTA-producing organisms present in nature, the green unicellular freshwater alga $H$. pluvialis is probably the source of ASTA most explored worldwide (Guerin et al., 2003). Adverse/stress growth conditions are imposed on $H$. pluvialis in order to exacerbate ASTA production in bioreactors, which can reach yields of ASTA (mono- and di-) esters of up to $98 \%$ of the total carotenoid content and around $4 \%$ of total dry cell weight (Jaime et al., 2010). Commercially grown $H$. pluvialis can accumulate more than $30 \mathrm{~g}$ ASTA/kg of dry biomass (Li et al., 2010).

\section{Exercise and oxidative stress}

Moderate daily exercise is known to be beneficial to health, especially for reducing the risks of infections and of a large number of degenerative (agerelated) disorders. Aerobic exercise is associated with a substantial increase in $\mathrm{O}_{2}$ uptake by contractile muscles (up to 80-fold higher in oxygen volume), activation of oxidative mitochondrial metabolism and, thus, increased production of ROS (Powers et al., 2010). The biochemical mechanisms by which regular exercise exerts its beneficial effects are not fully understood. One of the most accepted theories refers to a retrograde response called mitohormesis: the constant but moderate increase in mitochondrial formation of ROS is chronically responded to by antioxidant adaptations that result in an upgraded stress resistance and ultimately limit the accumulation of oxidative damage within the intracellular environment. Hence, this mechanism should sustain longer periods of optimized mitochondrial function, described biochemically as a positive ATPsupply/oxidative damage ratio within cells (Ristow \& Zarse, 2010). Based on the mitohormesis principle, it is likely that regular moderate exercise could upgrade overall antioxidant and repair systems - through redoxsignaling pathways - offering an acquired protection against further ROS exposure provoked by opportunist infectious and chronic inflammation processes $(\mathrm{Ji}$, 2008).

In contrast, prolonged and/or strenuous physical exertion is notably detrimental to health because massive amounts of ROS are abruptly produced under these circumstances (Banerjee et al., 2003). An overproduction of ROS that is not counterbalanced by an appropriate antioxidant capacity results in oxidative stress, a deleterious process that can be an important mediator of damage to cell structures, including lipids and membranes, proteins, and DNA (Gomez-Cabrera et al., 2009). Contractile ischemiareperfusion, thermal stress, dehydration, and osmotic imbalances can also exacerbate ROS formation during exercise (Martins et al., 2008). Taken together, redox imbalances during muscular contractions contribute significantly to the reduction of the contractility force, speed up the fatigue processes, and contribute to an increase in muscular injuries (Purvis et al., 2010).

In addition to the major role of mitochondrial electron leakage during aerobic exercise, it has been suggested that oxidative stress may be mediated through various other pathways: xanthine oxidase and NADPH oxidase activation, prostanoid metabolism, ischemia/ reperfusion, phagocytic respiratory burst activity, disruption of iron-containing proteins, and alteration of $\mathrm{Ca}^{2+}$ homeostasis (Jackson, 2000). The production of ROS via these pathways is also attributed to anaerobic exercise (e.g., isometric, eccentric, resistance, and sprint training) which may result in part from eccentric muscle actions, commonly followed by muscle injury (McHugh et al., 1999). Sprint exercise was and is still used as a form of anaerobic work to study oxidative stress responses. In the mid-1980's, Alessio et al. (1988) examined lipid peroxidation in rat skeletal muscle immediately following a 1-min sprint performed at $45 \mathrm{~m} / \mathrm{min}$ by using the classic TBARS method (Fraga et al., 1988) and measuring total lipid hydroperoxides (LOOH). More recently, Kayatekin et al. (2002) induced mice to perform fifteen sprints at $35 \mathrm{~m} / \mathrm{min}$ for $30 \mathrm{~s}$ each so that they could study oxidative stress in both skeletal muscle and the liver during the $24 \mathrm{~h}$ postexercise period. While lipid oxidation increased acutely (i.e., at $30 \mathrm{~min}$ and $3 \mathrm{~h}$ post-exercise) in skeletal muscle, no change was noted in the liver, suggesting a tissuespecific response. The majority of studies investigating dynamic resistance exercise-induced oxidative stress have utilized an exercise protocol consisting of two or more compound lifts (multiple joint exercises), occasionally performed in a circuit fashion (Ramel et al., 2004; McAnulty et al., 2005), usually $\geq 3$ sets at an intensity of $60-95 \%$ of one repetition maximum (Rietjens et al., 2007). Intense acute resistance exercise is frequently followed by elevation in blood oxidative stress markers. Accordingly, partial occlusion imposes ischemia artificially and also results in increases in ROS production and protein/lipid modifications (Tsutsumi et al., 2007). 
Muscle damage is characterized by ultrastructural changes to muscle architecture, increased muscle proteins and enzymes in the bloodstream (e.g., creatine kinase and lactate dehydrogenase are classic biomarkers of muscle injury), loss of muscular strength and range of motion and muscle soreness. Postexercise muscle injury is accompanied by: i) impaired/ exhausted antioxidant defense systems; ii) release of pro-inflammatory arachidonic acid, prostaglandins, and other cytokines (e.g., IL-6, IL-1 $\beta$ ); iii) release of hemoglobin (from hemolysis) and myoglobin (from rhabdomyolysis) and related 'free' iron ions; iv) neutrophil migration, activation and, thus, subsequent late onset re-exposure to oxidative conditions (Peake \& Suzuki, 2004). Nonetheless, much controversy has arisen as to whether strenuous exercise does, in fact, increase the need for additional antioxidants in the diet, as has been extensively recommended by scientists and companies involved in the marketing of dietary antioxidant supplements for athletes (Peake et al., 2007; Urso \& Clarkson, 2003).

It had been sugested that ROS levels during exercise should be kept within an optimal range in order to trigger important ROS-mediated processes, such as muscle tissue acquired antioxidant adaptations and redox-sensitive gene expression, while simultaneously avoid extreme oxidative damage to cellular structures (Gomez-Cabrera et al., 2005). Teixeira et al. (2009) showed that antioxidant supplementation indeed resulted in higher plasma levels of $\alpha$-tocopherol and $\beta$-carotene in athletes. After bouts of exercise, pro-inflammatory IL-6, TBARS, and uric acid also increased, regardless of the treatment group. Interestingly, cortisol levels increased more between the pre- and the post-supplementation periods in the placebo group. The authors reported that antioxidant supplementation did not offer protection against exercise-induced lipid peroxidation and inflammation and might even have hindered the recovery from muscle damage (Teixeira et al., 2009). Regarding antioxidant supplementation, key factors such as bioavailability, pharmacodynamic properties, and target-tissues are fundamental to establish the adequate oral dose for an antioxidant to match the narrow range of optimal in situ concentrations that sustain the redox balance in contractile skeletal muscles. A much more complicated system is expected when a combination of antioxidants is administered, since molecular interactions could occur within organs, tissues, cells, and intracellular compartments (Augustyniak et al., 2010).

\section{Astaxanthin and exercise}

Preliminary studies have found that ASTA can attenuate exercise-induced damage in mouse skeletal muscle and heart, in parallel with the modulation of post-exercise neutrophil infiltration and attenuation of delayed-onset muscular soreness in trained individuals (Aoi et al., 2003). On the other hand, other controversial results in resistance-trained men indicate that ASTA supplementation does not favorably affect indirect markers of skeletal muscle injury following eccentric loading (Bloomer et al., 2005). Regarding metabolic responses, Aoi et al. (2008) showed that ASTA: i) stimulated lipid oxidation as an energy-supplying substrate for extended exercise in detriment to glucose utilization; ii) inhibited the elevation of plasma lactate and reduced muscle glycogen catabolism during physical activity; and iii) increased the co-localization of fatty-acid translocase (FAT/CD36) with carnitinepalmitoyltransferase I (CPT I), enhancing its lipolytic effect associated with exercise. Ikeuchi et al. (2006) showed that the increase in plasma creatine kinase activity (a biomarker of muscle injury) was inhibited by treatment with ASTA, in parallel with the observed delay in muscle fatigue and endurance enhancement. Furthermore, a whole blood transit time evaluation performed in humans after administration of $6 \mathrm{mg}$ ASTA/daily for ten days showed a significant decrease of $10 \%$ in the rheological properties of blood with putative implications of a lower risk of thrombosis and atherosclerotic plaque formation (Miyawaki et al., 2008).

Two decades ago, elegant immunological studies carried out by Jyonouchi et al. (1991) showed that ASTA enhances in vitro antibody production by mouse spleen cells when stimulated by sheep erythrocytes. The authors assumed that the main targets of ASTA action were T-cells, especially T-helper cells (Jyonouchi et al., 1993; Jyonouchi et al., 1995). Significantly, such immunomodulating properties are retinol-independent since ASTA, unlike $\beta$-carotene, does not exhibit provitamin A activity (Jyonouchi et al., 1994). Despite several works directly link ASTA to immunecompetence, information on the pharmacological mechanisms by which ASTA might improve immune functions is still scarce.

\section{Astaxanthin and cognitive properties}

Recent findings have associated ASTA with putative benefits in exercise practice and eventually athletic performance, which also includes improvement of cognitive capacity. However, it is still unclear whether ASTA directly crosses the brain-blood barrier (BBB) or not (Tso \& Lam, 1996). Liu \& Osawa (2009) claim that ASTA not only crosses the BBB but also develops neuroprotective effects to dopaminergic SH-SY5Y cells against oxidative damage provoked by neurotoxic 6-hydroxydopamine. Furthermore, ferritin-aggregates 
in mutant neuroblastoma cells - a cellular model for degenerative neuroferritinopathies - were inhibited by in vitro treatment with $20 \mu \mathrm{M}$ ASTA (Cozzi et al., 2010).

\section{Concluding remarks}

Based on recently published literature, we conclude that consumption of ASTA obtained from natural sources (salmon, shrimp, krill oil etc) or via dietary supplements (from biotechnologically manufactured $H$. pluvialis biomass) might be a practical and beneficial strategy in exercise practice and health management. This is based on a consideration of the high antioxidant and anti-inflammatory activities of ASTA, although additional biological properties, like amelioration of cognitive capacity, have also been recently suggested. Further mechanistic studies focusing on the role of ASTA in exercise and physiopathological processes, especially neurodegenerative and modernlife diseases (diabetes, obesity, occupational stress), remain an open field for researchers involved in the Free Radical field.

\section{Acknowledgements}

The authors are indebted to the Fundação de Amparo a Pesquisa do Estado de São Paulo (Projects n. 2002/09405-9 and 2009/12342-8, FAPESP, Brazil), Coordenação de Aperfeiçoamento de Pessoal de Nível Superior, Brazil, International Foundation for Science (Project F/3618-1, IFS, Sweden) and the Conselho Nacional de Desenvolvimento Científico e Tecnológico (Bolsa Produtividade em Pesquisa, Nivel 2, n. 312404/2009-3, CNPq, Brazil,) for research funding and financial support.

\section{References}

Alessio HM, Goldfarb AH 1988. Lipid peroxidation and scavenger enzymes during exercise: adaptive response to training. J Appl Physiol 64:1333-1336.

Andersson M, Van Niewerburgh L, Snoeijs P 2003. Pigment transfer from phytoplankton to zooplankton with emphasis on astaxanthin production in the Baltic Sea food web. Mar Ecol-Prog Ser 254: 213-224.

Aoi W, Naito Y, Sakuma K, Kuchide M, Tokuda H, Maoka T, Toyokuni S, Oka S, Yasuhara M, Yoshikawa T 2003. Astaxanthin limits exercise-induced skeletal and cardiac muscle damage in mice. Antioxid Redox Signal 5: 139-144.

Aoi W, Naito Y, Takanami Y, Ishii T, Kawai Y, Akagiri S, Kato Y, Osawa T, Yoshikawa T 2008. Astaxanthin improves muscle lipid metabolism in exercise via inhibitory effect of oxidative CPT I modification.
Biochem Biophys Res Commun 366: 892-897.

Augustyniak A, Bartosz G, Cipak A, Duburs G, Horáková L, Luczaj W, Majekova M, Odysseos AD, Rackova L, Skrzydlewska E, Stefek M, Strosová M, Tirzitis G, Venskutonis PR, Viskupicova J, Vraka PS, Zarković N 2010. Natural and synthetic antioxidants: an updated overview. Free Radic Res 44:1216-1262.

Banerjee AK, Mandal A, Chanda D, Chakraborti S 2003. Oxidant, antioxidant and physical exercise. Mol Cell Biochem 253: 307-312.

Barros MP, Pinto E, Colepicolo P, Pedersen M 2001. Astaxanthin and peridinin inhibit oxidative damage in $\mathrm{Fe}(2+)$-loaded liposomes: scavenging oxyradicals or changing membrane permeability? Biochem Biophys Res Commun 288: 225-232.

Bloomer RJ, Fry A, Schilling B, Chiu L, Hori N, Weiss L 2005. Astaxanthin supplementation does not attenuate muscle injury following eccentric exercise in resistance-trained men. Int J Sport Nutr Exerc Metab 15: 401-412.

Bolin AP, Macedo RC, Marin DP, Barros MP, Otton R 2010. Astaxanthin prevents in vitro auto-oxidative injury in human lymphocytes. Cell Biol Toxicol 26: 457-467.

Cardozo KH, Guaratini T, Barros MP, Falcão VR, Tonon AP, Lopes NP, Campos S, Torres MA, Souza AO, Colepicolo P, Pinto E 2007. Metabolites from algae with economical impact. Comp Biochem Physiol C Toxicol Pharmacol 146: 60-78.

Choi HD, Kang HE, Yang SH, Lee MG, Shin WG 2011. Pharmacokinetics and first-pass metabolism of astaxanthin in rats. Brit J Nutr 105: 220-227..

Christiansen R, Lie O, Torrissen OJ 1995. Growth and survival of Atlantic salmon, Salmo salar L., fed different dietary levels of astaxanthin. First-feeding fry. Aquacult Nutr 1: 189-198.

Cort A, Ozturk N, Akpinar D, Unal M, Yucel G, Ciftcioglu A, Yargicoglu P, Aslan M 2010. Suppressive effect of astaxanthin on retinal injury induced by elevated intraocular pressure. Regul Toxicol Pharmacol 58: 121-130.

Cozzi A, Rovelli E, Frizzale G, Campanella A, Amendola M, Arosio P, Levi S 2010. Oxidative stress and cell death in cells expressing L-ferritin variants. Neurobiol Dis 37: 77-85.

Del Campo JA, García-González M, Guerrero MG 2007. Outdoor cultivation of microalgae for carotenoid production: current state and perspectives. Appl Microbiol Biotechnol 74: 1163-1174.

Fassett RG, Coombes JS 2009. Astaxanthin, oxidative stress, inflammation and cardiovascular disease. Future Cardiol 5: 333-342.

Fraga CG, Leibovitz BE, Tappel AL 1988. Lipid peroxidation measured as thiobarbituric acid-reactive substances in tissue slices: characterization and comparison with homogenates and microsomes. Free Radic Biol Med 
Ikeuchi M, Koyama T, Takahashi J, Yazawa K 2006. Effects of astaxanthin supplementation on exercise-induced fatigue in mice. Biol Pharm Bull 29: 2106-2110.

Ikeuchi M, Koyama T, Takahashi J, Yazawa K 2007. Effects of astaxanthin in obese mice fed a high-fat diet. Biosci Biotechnol Biochem 71: 893-899.

Jackson MJ 2000. Exercise and oxygen radical production by muscle. (Sen CK, Packer L, Hanninen O, eds.) Amsterdam: Elsevier Science.

Jaime L, Rodriguez-Meizoso I, Cifuentes A, Santoyo S, Suarez S, Ibáñez E, Señorans FJ 2010. Pressurized liquids as an alternative process to antioxidant carotenoids extraction from Haematococcus pluvialis microalgae. LTW-Food Sci Technol 43: 105-112.

Ji LL 2008. Modulation of skeletal muscle antioxidant defense by exercise: Role of redox signaling. Free Radic Biol Med 44: 142-152.

Jin E, Polle JEW, Lee HK, Hyun SM, Chang M 2003. Xanthophylls in microalgae: From biosynthesis to biotechnological mass production and application. $J$ Microbiol Biotechnol 13: 165-174.

Jyonouchi H, Hill RJ, Tomita Y, Good RA 1991. Studies of immunomodulating actions of carotenoids. I. Effects of beta-carotene and astaxanthin on murine lymphocyte functions and cell surface marker expression in vitro culture system. Nutr Cancer 16: 93-105.

Jyonouchi H, Zhang L, Tomita Y 1993. Studies of immunomodulating actions of carotenoids. II. Astaxanthin enhances in vitro antibody production to T-dependent antigens without facilitating polyclonal B-cell activation. Nutr Cancer 19: 269-280.

Jyonouchi H, Zhang L, Gross M, Tomita Y 1994. Immunomodulating actions of carotenoids: enhancement of in vivo and in vitro antibody production to T-dependent antigens. Nutr Cancer 21: 47-58.

Jyonouchi H, Sun S, Gross M 1995. Effect of carotenoids on in vitro immunoglobulin production by human peripheral blood mononuclear cells: astaxanthin, a carotenoid without vitamin A activity, enhances in vitro immunoglobulin production in response to a T-dependent stimulant and antigen. Nutr Cancer 23: 171-183.

Kamath BS, Srikanta BM, Dharmesh SM, Sarada R, Ravishankar GA 2008. Ulcer preventive and antioxidative properties of astaxanthin from Haematococcus pluvialis. Eur J Pharmacol 590: $387-$ 395.

Kayatekin BM, Gonenc S, Acikgoz O, Uysal N, Dayi A 2002. Effects of sprint exercise on oxidative stress in skeletal muscle and liver. Eur J Appl Physiol 87: 141-144.

Li Y, Sommerfeld M, Chen F, Hu Q 2010. Effect of photon flux densities on regulation of carotenogenesis and cell viability of Haematococcus pluvialis
(Chlorophyceae). J Appl Phicol 22: 253-263.

Liu X, Osawa T 2009. Astaxanthin protects neuronal cells against oxidative damage and is a potent candidate for brain food. Forum Nutr 61: 129-135.

Martins AS, Shkryl VM, Nowycky MC, Shirokova N 2008. Reactive oxygen species contribute to $\mathrm{Ca} 2+$ signals produced by osmotic stress in mouse skeletal muscle fibres. J Physiol 586: 197-210.

McAnulty SR, McAnulty LS, Nieman DC, Morrow JD, Utter AC, Dumke CL 2005. Effect of resistance exercise and carbohydrate ingestion on oxidative stress. Free Radic Res 39: 1219-1224.

McHugh MP, Connolly DA, Eston RG, Gleim GW 1999. Exercise-induced muscle damage and potential mechanisms for the repeated bout effect. Sports Med 27: 157-170.

Miao L, Chi S, Tang Y, Su Z, Yin T, Guan G, Li Y 2010. Astaxanthin biosynthesis is enhanced by high carotenogenic gene expression and decrease of fatty acids and ergosterol in a Phaffia rhodozyma mutant strain. FEMS Yeast Res, doi: 10.1111/j.15671364.2010.00705.x.

Miyawaki H, Takahashi J, Tsukahara H, Takehara I 2008. Effects of astaxanthin on human blood rheology. $J$ Clin Biochem Nutr 43: 69-74.

Nagao A 2009. Absorption and function of dietary carotenoids. Forum Nutr 61: 55-63.

Nakao R, Nelson OL, Park JS, Mathison BD, Thompson PA, Chew BP 2010. Effect of dietary astaxanthin at different stages of mammary tumor initiation in BALB/c mice. Anticancer Res 30: 2171-2175.

Odeberg JM, Lignell A, Pettersson A, Höglund P 2003. Oral bioavailability of the antioxidant astaxanthin in humans is enhanced by incorporation of lipid based formulations. Eur J Pharm Sci 19: 299-304.

Otton R, Marin DP, Bolin AP, Santos RCM, Polotow TG, Sampaio SC, Barros MP 2010. Astaxanthin ameliorates the redox imbalance in lymphocytes of experimental diabetic rats. Chem Biol Interact 186 : 306-315.

Palozza P, Krinsky NI 1992. Astaxanthin and canthaxanthin are potent antioxidants in a membrane model. Arch Biochem Biophys 297: 291-295.

Peake J, Suzuki K 2004. Neutrophil activation, antioxidant supplements and exercise-induced oxidative stress. Exerc Immunol Rev 10: 129-141.

Peake JM, Suzuki K, Coombes JS 2007. The influence of antioxidant supplementation on markers of inflammation and the relationship to oxidative stress after exercise. J Nutr Biochem 18: 357-371.

Petri D, Lundebye AK 2007. Tissue distribution of astaxanthin in rats following exposure to graded levels in the feed. Comp Biochem Physiol C Toxicol Pharmacol 145: 202-209.

Polyakov NE, Focsan AL, Bowman MK, Kispert LD 2010. 
Free radical formation in novel carotenoid metal ion complexes of astaxanthin. J Phys Chem B 114: 1696816977.

Powers SK, Nelson WB, Hudson MB 2010. Exerciseinduced oxidative stress in humans: Cause and consequences. Free Radic Biol Med, doi:10.1016/j. freeradbiomed.2010.12.009.

Purvis D, Gonsalves S, Deuster PA 2010. Physiological and psychological fatigue in extreme conditions: overtraining and elite athletes. PM R 2: 442-450.

Ramel A, Wagner KH, Elmadfa I 2004. Plasma antioxidants and lipid oxidation after submaximal resistance exercise in men. Eur J Nutr 43: 2-6.

Rao AV, Rao LG 2007. Carotenoids and human health. Pharmacol Res 55: 207-216.

Rietjens SJ, Beelen M, Koopman R, LJ VANL, Bast A, Haenen GR 2007. A single session of resistance exercise induces oxidative damage in untrained men. Med Sci Sports Exerc 39: 2145-2151.

Ristow M, Zarse K 2010. How increased oxidative stress promotes longevity and metabolic health: The concept of mitochondrial hormesis (mitohormesis). Exp Gerontol 45: 410-418.

Stewart JS, Lignell A, Pettersson A, Elfving E, Soni MG 2008. Safety assessment of astaxanthin-rich microalgae biomass: Acute and subchronic toxicity studies in rats. Food Chem Toxicol 46: 3030-3036.

Teixeira VH, Valente HF, Casal SI, Marques AF, Moreira PA 2009. Antioxidants do not prevent postexercise peroxidation and may delay muscle recovery. Med Sci
Sports Exerc 41: 1752-1760.

Tso MOM, Lam TT 1996. Method of retarding and ameliorating Central Nervous System and eye damage. US 5,527,533.

Tsutsumi YM, Yokoyama T, Horikawa Y, Roth DM, Patel HH 2007. Reactive oxygen species trigger ischemic and pharmacological postconditioning: in vivo and in vitro characterization. Life Sci 81: 1223-1227.

Urso ML, Clarkson PM 2003. Oxidative stress, exercise, and antioxidant supplementation. Toxicology 189: 41-54.

Wolf AM, Asoh S, Hiranuma H, Ohsawa I, Iio K, Satou A 2010. Astaxanthin protects mitochondrial redox state and functional integrity against oxidative stress. $J$ Nutr Biochem 21: 381-389.

Yoshida H, Yanai H, Ito K, Tomono Y, Koikeda K, Tsukahara $\mathrm{H}$, Tada N 2010. Administration of natural astaxanthin increases serum HDL-cholesterol and adiponectin in subjects with mild hyperlipidemia. Atherosclerosis 209: 520-523.

\section{*Correspondence}

Marcelo P. Barros

Programa de Pós-graduação Ciências do Movimento Humano, Instituto de Ciências da Atividade Física e Esporte, Universidade Cruzeiro do Sul, 01506-000 São Paulo-SP, Brazil

marcelo.barros@cruzeirodosul.edu.br

Tel.: +551133853015

Fax: +55 1120375700 